Música da Antiguidade e do

Medievo: Performance, recepção

e recriação

\title{
A Teatralidade Ibérica em algumas canções de Juan del Encina
}

Iberian Theatricality in Select

Songs by Juan del Encina

Werner Ewald

E-mail:wernerew1311@gmail.com

João A. Straub Gomes

joaolexandrem6@hotmail.com

Marcelo Borba

E-mail: marcelopercussao@hotmail.com

Leonora Oxley

E-mail: loloxley@terra.com.br

Carlos W. Soares

E-mail: carloswasoares@gmail.com

Centro de Artes - Universidade Federal de Pelotas (UFPel) 


\section{Resumo}

Poeta, músico e dramaturgo do pré-renascimento espanhol, Juan del Encina (14681529) foi patriarca e um dos mais importantes fundadores da dramaturgia ibérica. A veia teatral de sua obra musical apresenta, por um lado, ainda uma direta continuação do Auto Medieval, composição teatral de linguagem simples e extensão curta, e por outro uma já distinguida qualidade Renascentista. Seus poemas são concebidos para serem cantados e cada um deles forma um brevíssimo e sintético ato dramático. A forma literário-musical do Romance é largamente utilizada na obra de Encina, que se encontra também desmembrada em outras formas como as Cantigas, as Tonadas e os Villancicos signos de uma obra marcadamente étnica. De inspiração popular, sua obra transita entre eras de tradição oral e escrita da transmissão das habilidades e da cultura musical. Os textos e a música de Encina compõem uma unidade expressa em melodias pungentes e ritmos fortes através da força dramática de temáticas como 0 amor, a dor, a religiosidade, e a sátira. Estudando e considerando todos estes importantes elementos criadores e instituidores da obra de Encina, propomos uma análise macroestrutural visando o arranjo e a performance musical comentada de algumas canções do referido autor, exemplificando e trazendo a tona o vigor e a dramaticidade contextual do teatro musical espanhol na obra de Juan del Encina.

Palavras-chave: Juan del Encina, Música Antiga, História da Música Ibérica.

\section{Abstract}

Poet, musician and playwright of the Spanish pre-Renaissance, Juan del Encina (1468-1529) was patriarch and one of the most important founders of Iberian dramaturgy. The theatrical vein of his musical work presents, on the one hand, a direct continuation of the Medieval (actus) drama, and on the other, an already distinguished Renaissance quality. Encina's poems are intended to be sung, each forming a brief and synthetic dramatic act. The literary-musical form Romance is widely used in the work of Encina. His work can also be sub-classified into other forms such as Cantigas, Tonadas and Villancicos, signs of a markedly ethnic work. Of popular inspiration, Encina's work transits between a period of oral and written musical skills and culture. His texts and music compose a unit expressed in pungent melodies and strong rhythms through the dramatic force of themes such as love, suffering, religiosity, and satire. Through a studying that considers all the above important creative and instituting elements of Encina's work, we propose a macro-structural analysis aiming the arrangement and the musical performance of a selection of pieces by the author. We also propose to include illustrative comments on this song selection, to highlight the vigor and contextual dramaticity of Spanish musical theater in the work of Juan del Encina.

Keywords: Juan del Encina, Ancient Music, History of Iberian Music. 
uan del Encina, espanhol, nasceu em 1468 e morreu cerca de 1530 sendo, portanto, um autor do pré-renascimento espanhol e considerado precursor da dramaturgia Ibérica. Poeta, músico e dramaturgo, este autor tem uma obra caracterizada por uma original fusão onde texto, música e dança se entrecruzam constantemente na elaboração de um tipo de arte de representação. Nela podemos verificar que estão presentes duas dimensões. Primeiramente, o auto medieval pode ser identificado nas características de uma composição teatral de linguagem simples e extensão curta. E por outro lado, a música apresenta distinguidas qualidades renascentistas, como o uso de passagens polifônicas e madrigalismos, recursos técnico-composicionais estes, típicos do renascimento europeu.

Juan Del Encina concebeu seus poemas para serem cantados/recitados e dramatizados com a particular característica de serem brevíssimos e sintéticos atos dramáticos. Para exemplificar, selecionamos duas de suas canções: "Levanta, Pascual" e "Oy Comamos y Bebamos." Abordaremos estas duas obras de modo macro-textual e estrutural. Nosso objetivo é realizar uma abordagem que contemple a dimensão intertextual e o panorama estético-estilístico das obras. Uma análise descritiva que se debruce em cada microestrutura seria mais apropriada para outros objetivos (WHITE, 1976). No entanto, algumas estruturas menores (intermediárias e micro) serão expostas para contextualização e clareza.

Nas duas canções em foco Juan del Encina lança mão de recursos expressivos de texto (poéticos) e rítmico-musicais que apresentam possibilidades diversas para uma representação cênica. Podemos citar como exemplos a descrição de situações dramáticas e satíricas, a movimentação e o diálogo de diferentes personagens, além de procedimentos musicais específicos utilizados deliberadamente para contribuir e enriquecer a perspectiva poético-literária.

A peça "Levanta Pascual" é um Romance. Romances são composições dramáticas escritas por músicos e escritores profissionais, na maioria das vezes para celebrar determinadas personalidades e/ou acontecimentos especiais, como bem exemplifica a canção "Levanta Pascual" especialmente escrita para cantar as proezas dos exércitos de Dona Isabel de Castela (1451-1504) e Dom Ferdinando II de Aragão (1469-1504), os monarcas de Castela, chamados também de os Reis Católicos. É digno de ser observado que Juan del Encina é o poeta-músico mais prolífico do reinado deste casal de monarcas espanhol (WHETNALL, 2017:88). ${ }^{?}$

Esta composição foi dedicada à capitulação da cidade de Granada, situada na região da Andaluzia, Espanha. Fundada em 756 pelos árabes, desde o sécu-

1 As obras de Encina encontram-se registradas em vários Cancioneros sendo, no entanto, o que contém o maior número de suas canções o "Cancionero Musical de Palácio". Este manuscrito é a maior de todas as fontes de canções seculares espanholas desta época. Contém um total de quatrocentos e trinta e oito obras de autores vários e foi compilado nos anos de 1490 para a corte de Isabel e Ferdinando. 
lo XIII era a capital do reino muçulmano de Granada. A sua rendição, celebrada durante vários dias, é o culminar de dez anos de guerras (1482-1492) encerrando um ciclo de oito séculos de domínio muçulmano na Península Ibérica. "Levanta Pascual" foi composta para o festejo musical e dramático relativo a este evento histórico que gerou enorme literatura. Composta no dramático gênero Romance, esta canção inclui recitados, polifonia semi-improvisada, frases com cadências finais bem marcadas, acompanhamento instrumental em geral homofônico e participação de um coro em alternâncias entre canto solista e em grupo. Todos estes elementos expressivos são característicos da pioneira teatralidade Ibérica de Juan de Encina, apresentando singulares soluções musicais para a interpretação de canções dramatizadas onde se requeria que atores cantassem e dançassem na execução das peças².

Em "Levanta Pascual", percebemos que justamente em torno das palavras "levanta, Pascual" o contorno melódico da frase musical é ascendente, fazendo referência ao seu significado literal. E no verso seguinte, cujo texto é "aballemos a Granada", o contorno melódico da frase musical é descendente, em alusão ao descenso geográfico do caminho em direção a Granada:

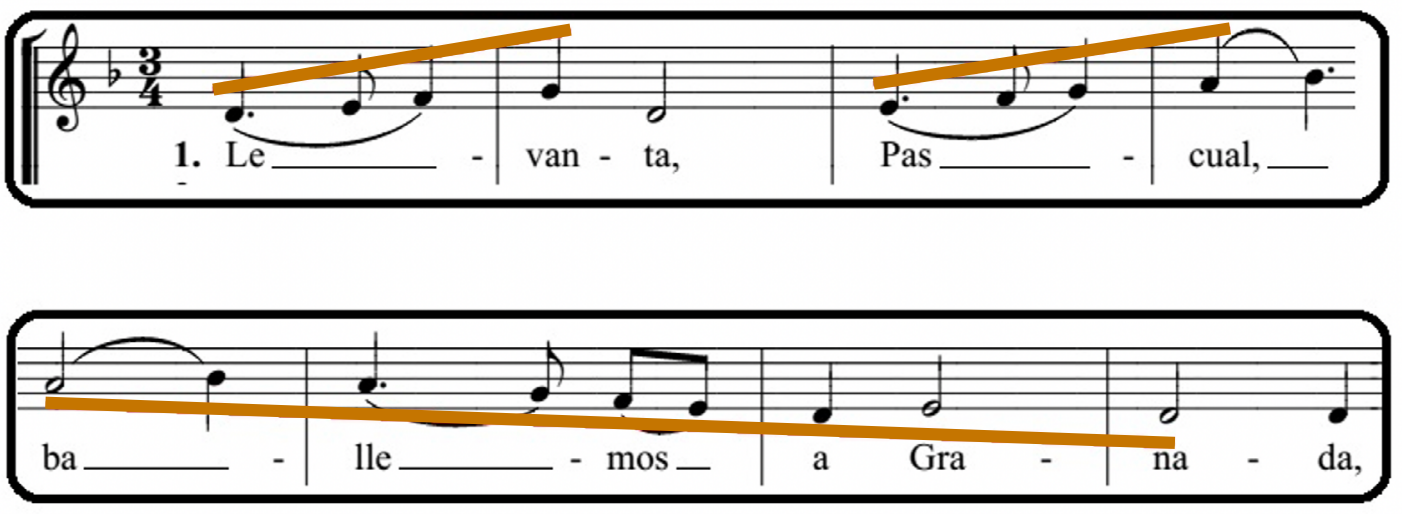

Figura 1: Técnica composicional de movimentação melódica ilustrativa

Nesses momentos Juan del Encina utilizou um procedimento composicional que seria largamente utilizado na renascença em vários países da Europa. Tal procedimento, em que a movimentação melódica encontra paralelismo na dimensão verbal do texto da canção, é típico da retórica de representação na música renascentista (SHUTE, 1972). O teórico inglês Charles Butler (1560-1647) fez o registro de algumas das convenções da época em duas obras, intituladas "Rhetoricae Libri duo" (1629) e "Principles of Musik" (1636). Esse paralelismo observado é uma das modalidades de elaboração da técnica de word-paint. Por

2 Além de na obra de Juan de Encina, estas características podem ser encontradas também na obra de Gil Vicente (1465-1536), )considerado o primeiro dramaturgo português, além de grande poeta, músico e ator.

Revista do Laboratório de Dramaturgia / LADI - UnB Vol. 15, Ano 5 | Dossiê Música da Antiguidade e do Medievo: Performance, recepção e recriação 
vezes, a estrutura musical 'pinta' apenas uma determinada palavra e, outras vezes, a melodia 'pinta' ideias mais amplas como, por exemplo, a ascensão aos céus (GOMES, 2015).

Já a segunda peça trabalhada "Oy Comamos y Bebamos" explora especialmente as figuras rítmicas já que se trata de um baile de jiga. Embora seja uma antiga dança popular de marcado caráter de habilidades de improvisação, esta composição de Juan de Encina já se configura dentro de um período transacional de crescente produção e circulação de fontes e tratados musicais que se propõe a disseminar as antigas habilidades de improvisação musical, antes transmitidas oralmente por tratados e música escrita. É exatamente a época dos monarcas de Castela, Isabel e Ferdinando, que marca esta transição (FIORENTINO, 2017:547-48).

"Oy Comamos e Bebamos" é um villancico um gênero que, na maioria das vezes, exibe textos que evocam o dia a dia dos camponeses espanhóis. A música do villancico aqui em questão é planejada de modo a parecer rústica com texturas homofônicas e figuras rítmicas bem marcadas da jiga, uma dança rápida, saltitante e escrita geralmente em compasso 6/8 (BURKHOLDER; PALISCA: 2010: 288-89). Uma característica muito comum nesta dança é a apresentação de cadências finais com alguma variação na acentuação rítmica do compasso 6/8, de modo a sentirmos um ritmo ternário, então em 3/4:

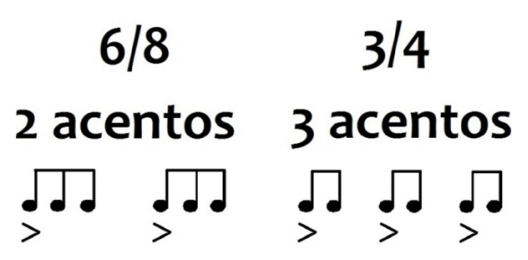

Figura 2: Acentuação rítmica de compassos binários compostos e ternários simples

Como podemos observar na imagem, ambas as fórmulas de compasso são formadas pela quantidade de colcheias e cada uma delas dura o mesmo tempo. No entanto, a maneira como a acentuação das colcheias acontece proporciona encadeamentos rítmicos e ideia de movimentação distintas. Nos compassos em binário composto, há dois acentos principais, que repousam sobre a primeira e quarta colcheias. Enquanto isso, os compassos ternários simples apresentam uma subdivisão em que três acentos marcam a primeira, terceira e quinta colcheias.

O recurso de variação na acentuação, preservando-se a quantidade de colcheias que compõe o compasso, é chamado de hemíola. As hemíolas também são utilizadas quando a música é escrita em $3 / 4$, sendo que nesse caso os compassos finais têm sua acentuação alterada para 6/8. Em "Oy Comamos y Bebamos", Juan del Encina explora de modo distinto as duas características mencionadas 
da dança de jiga, ou seja, o andamento movido e a estrutura da hemíola. Aqui a alternância entre o 3/4 e o 6/8 como recurso de variação na acentuação rítmica não está restrito às finalizações das frases, mas sim é um elemento estrutural da métrica de versificação já que se trata de uma canção.

Pelo seu conteúdo literário é uma peça da religiosidade popular em que em uma poesia burlesca é estendido um convite para que todos encham suas panças e comam até explodir em honra ao santo. A ocasião invocada é a Terça-feira Gorda, véspera da Quarta-feira de Cinzas, período do calendário litúrgico cristão que tem inicio o jejum da Quaresma³. Embora de conotação religiosa (popular) o texto é burlesco enfatizando através da sátira que somente depois, amanhã, na Quarta-feira de Cinzas, pensaremos no jejum. Hoje, na Terça-feira Gorda é tempo de comer, beber e dançar e é isso que importa. É neste ambiente de teatralidade festiva que está inserida a peça "Oy Comamos y Bebamos" de Juan del Encina. Para ressaltar a sua dramaticidade popular e festiva nela acontece movimentação, algazarra, dança e barulho de feira popular. Deste lócus projetamos recursos de interpretação musical para iluminar seu caráter e tornar palpável seu conteúdo dramático e emocional em nossas performances musicais.

De inspiração popular, os textos, a ação e a música de Juan del Encina compõem uma unidade expressa em melodias pungentes e ritmos fortes através da força dramática de temáticas como o amor, a dor, a religiosidade, e a sátira. Estudando e considerando todos estes elementos criadores e instituidores da obra de Encina, propomos como grupo de pesquisa e execução musical que somos (Grupo Iluminura - Centro de Artes - UFPEL) o arranjo e a performance musical com comentários ilustrativos, exemplificando o vigor e a dramaticidade contextual do teatro musical espanhol na obra de Juan del Encina.

Para finalizar, destacamos que em nosso trabalho de pesquisa e performance musical, nos guiamos pelo princípio de que toda interpretação representa não a escolha de algum ideal, mas uma escolha. Deixamo-nos guiar pela perguntas: quais das relações implícitas numa peça precisam ser enfatizadas e reveladas? Quais os meios que dispomos de projetá-los? É neste sentido que nos percebemos enquanto artista músicos co-criadores do material musical com o qual nos ocupamos em nosso trabalho de pesquisas em música tradicional e antiga.

\section{Referências}

BURKHOLDER, J. Peter; PALISCA, Claude V. (eds.). Norton Anthology of Western Music, v.1: Ancient to Baroque, 6eed. New York/London. W.W.Norton and Company, 2010.

3 Período de quarenta dias em que as comunidades cristãs se voltam à penitência em preparação para a Páscoa, sendo o jejum de comida e bebida um dos seus aspectos mais conhecidos. 
GOMES, João Alexandre Straub. A Representação da Melancolia nas Ayres de John Dowland. 163f. Dissertação (Mestrado em Música), Universidade Federal do Paraná. Curitiba, 2015.

FIORENTINO, Giuseppe. "Unwritten Music and Oral Traditions at the Time of Ferdinand and Isabel". In: Companion to Music in the Age of Catholic Monarchs. Tess Knighton (ed.). Leiden/Boston: Brill, 2017, pp.504-548.

SHUTE, John Derek. The English Theorists of the Seventeenth Century with Particular Reference to Charles Butler and the Principles of Musik in Singing and Setting 1636. 252f. Tese (Master of Letters), Durham University, England, 1972.

WHETNALL, Jane. "Secular Song in Fifteenth-Century Spain". In: Companion to Music in the Age of Catholic Monarchs. Tess Knighton (ed.). Leiden/ Boston: Brill, 2017, pp. 60-96.

WHITE, John. The analysis of music. New Jersey: Prentice-Hall, 1976. 